\title{
La frontera en Arauco en el siglo XVII: recursos, población, conocimiento y política imperial
}

\author{
Margarita Gascón \\ CRICYT-CONICET (Argentina) \\ gascon@lab.cricyt.edu.ar
}

\begin{abstract}
Resumen
La disponibilidad de recursos naturales brinda explicaciones sobre la evolución de las sociedades coloniales, especialmente en las fronteras porque, de diversas maneras, los recursos disponibles estructuraron las relaciones sociales, desde el comercio hasta la guerra. El presente análisis explica algunos aspectos teóricos sobre los estudios de fronteras en general y luego explora las posibilidades que brinda un modelo que organiza los datos en tres esferas: población, recursos y conocimiento. Estas tres esferas, a su vez, interactúan en un campo de fuerzas determinado por las decisiones geopolíticas y estratégicas que se tomaban en la lejana metrópolis europea. El objetivo de este modelo es otorgar al ambiente, pero más especialmente a los recursos naturales, la misma importancia que los análisis históricos asignan al factor demográfico, al comercio, a la producción o a las decisiones políticas. El modelo finalmente se aplica a la frontera en Arauco, que fue militarizada desde principios del siglo XVII.

Palabras clave: FRONTERAS, RECURSOS, POBLACIÓN, CONOCIMIENTO, POLÍTICA IMPERIAL, ARAUCO, SIGLO XVII.
\end{abstract}

\begin{abstract}
The availability of natural resources provides us with explanations about the eventual outcome of the negotiations over a frontier. In many ways, the availability or lack of resources is responsible for the structures and patterns of most of the social relationships established because of a frontier zone, from trade to warfare. This paper first will explain some theoretical issues relating to frontiers in general, and then will explore a model of three spheres: people, resources, and knowledge. These three spheres interact in a field of force determined by the strategic decisions taken in the faraway metropolis. The aim of this model is to grant the environment, and the availability of resources in particular, equal importance with other factors such as demography, trade, production, and political decisions. Finally, the model will be applied to the frontier zone of Arauco; a frontier that became fortified in the early seventeenth century.
\end{abstract}

Key Words: FRONTIERS, RESOURCES, PEOPLE, KNOWLEDGE, EMPIRE POLICY, ARAUCO, $17^{\mathrm{TH}}$ CENTURY. 


\section{Introducción $^{1}$}

Con frecuencia nos interesa reconstruir aquellos procesos en los cuales una sociedad comienza a expandirse en búsqueda de más (o de nuevos) recursos materiales y humanos. Esa expansión, ocasionalmente, ocurre sobre territorios deshabitados, de modo que evita así entrar en conflicto con otras sociedades. Sin embargo, es más frecuente que la expansión se realice penetrando en tierras que ya tienen dueños y que están dispuestos a enfrentar y a defender sus derechos a la explotación de los recursos disponibles en esa área. En semejantes condiciones, surge una frontera, que es así el resultado de la lucha entre dos grupos que deben enfrentarse para decidir quién es el dueño de esa tierra y, por supuesto, quién es el dueño de sus recursos materiales y humanos.

La búsqueda de recursos naturales es parte de lo que varios estudios recientes sobre el ambiente han subrayado como uno de los elementos de mayor alcance explicativo de lo que han sido las sociedades en el pasado en sus relaciones con la naturaleza y en sus relaciones entre ellas mismas. El punto de partida es que existe un hecho básico en nuestras vidas: los seres humanos vivimos en ambientes que tienen un número limitado de recursos que deberemos explotar para satisfacer nuestras necesidades y nuestros apetitos. En el pasado, esta dependencia entre el ambiente y las sociedades hizo que éstas tuvieran diferentes actitudes y comportamientos. Varias sociedades culminaron esa relación con su ambiente en la parte negativa del balance, porque abusaron de la explotación de los recursos hasta su agotamiento y extinción. Tal explotación se basó muy a menudo en una equivocada creencia de que la disponibilidad del recurso era indefinida. Pero varias sociedades también cultivaron un respeto reverencial por la naturaleza, adorándola y cuidándola como su más importante y prodigioso bien. El conocimiento, entonces, sumado a la cantidad de recursos disponibles y a la presión demográfica son las tres esferas que deben considerarse para comprender los tipos de relaciones que hubo -y hay- entre las sociedades y sus ambientes.

En el caso de las fronteras en las Américas, la disponibilidad y explotación de los recursos naturales y humanos han sido también elementos decisivos para explicar sus surgimientos y sus sucesivas transformaciones. Para empezar, debemos preguntarnos por qué surgieron esas fronteras entre las sociedades nativas y los europeos. También necesitamos explicar sus patrones de evolución y los ingredientes que fueron operando en aquellas sucesivas transformaciones. De acuerdo al modelo teórico que proponemos, la cantidad de gente utilizando un mismo recurso, es decir, la interacción entre la esfera demográfica y la esfera de los recursos, junto con el conocimiento (esfera que incluye la tecnología) son tres ámbitos que nos permiten dar respuesta a esos interrogantes.

\footnotetext{
${ }^{1}$ Este texto se basa en una conferencia pronunciada en el Northern Indian College, Billingham, Washington State, en enero de 2003. Quiero agradecer al Dr. Roberto González Plaza por su invitación y su hospitalidad. La conferencia se financió dentro del programa OLP-Fulbright mientras me encontraba como profesora visitante en el Instituto de Estudios Latinoamericanos Teresa Lozano Long (ILAS) de la University of Texas at Austin como Fulbright Visiting Scholar.
} 
Todos los historiadores y las historiadoras pueden abundantemente testimoniar que cuando una sociedad se expande es porque está buscando más (o nuevos) recursos materiales y humanos. No existe, entonces, ninguna novedad en esta afirmación que puede rastrearse entre las explicaciones de las guerras y de los conflictos más antiguos de la humanidad. Más específicamente, el surgimiento y la evolución de una frontera podría relacionarse con la presión que una sociedad ejerce al ingresar en un territorio $\mathrm{y}$, frente a tal comportamiento, otra sociedad se resiste y protege sus bienes y personas. La expansión de los europeos en el siglo XV sobre los territorios ocupados por las sociedades nativas, entonces, explica el origen de las fronteras coloniales en las Américas cuando la expansión de los europeos finalmente encontraba algún tipo de resistencia por parte de los indígenas. Ni entonces ni ahora existen expansiones infinitas.

Pero los límites a la expansión son variados. Pueden existir límites al interior de una sociedad, es decir, límites que aparecen en el seno de la misma sociedad que ha iniciado su proceso de expansión. Entre estos límites internos está el factor demográfico nuevamente, porque por ejemplo, comienzan a escasear soldados o faltan las personas dispuestas a enrolarse en esas difíciles expediciones hacia nuevas tierras en búsqueda de riquezas o de gloria. A su vez, el factor demográfico influye también en otro sentido para frenar la expansión, y es que el drenaje de hombres hacia esas nuevas tierras debilita a las comunidades en las áreas centrales de un imperio y hay que tener presente que es en esas áreas centrales donde se ubica el motor mismo de tales expansiones. Estas zonas centrales, por supuesto, también necesitan suficiente mano de obra como para sostener las tareas cotidianas que son, a su vez, las que justifican e impulsan las expansiones.

Hay otros límites internos que provienen de la esfera de los recursos. Se trata de la disponibilidad de bienes materiales para proveer a esas expediciones expansivas. Por ejemplo, una expansión debe tener suficientes alimentos y suficientes medios de transporte; algo que sigue siendo válido aun en las guerras contemporáneas que están altamente tecnologizadas. Por último, la expansión militar del Imperio Romano ilustra la existencia de otro tipo de límite interno. Se trata de la creciente corrupción política y militar que suele erosionar la capacidad expansiva total de una sociedad. Como las expansiones son soportadas militarmente, éstos avanzan con sus valores y mentalidad sobre la sociedad civil y cuesta comenzar a separar la sociedad civil de la militar por la omnipresencia de la segunda sobre la primera ${ }^{2}$.

Como dijimos, además de los límites internos existen límites externos. Estos son límites geográficos tales como la existencia de océanos o de cadenas de montañas que en algún momento histórico pueden ser obstáculos imposibles de remontar debido a la falta del conocimiento apropiado, es decir, de las técnicas o de los elementos materiales apropiados. La esfera del conocimiento entonces puede adquirir en este lugar una relevancia explicativa fundamental.

\footnotetext{
${ }^{2}$ He analizado esta dimensión de la presencia de tropas en el caso de otra frontera colonial y después de la reforma militar de Carlos III. Margarita Gascón, “The Military of Santo Domingo, 1720-1764”, Hispanic American Historical Review 73, no. 3 (1993): 431-452.
} 
Todos estos límites, internos y externos, solos o combinados, hacen que una expansión llegue a su fin. En forma mucho más frecuente, sin embargo, nos concentramos en cómo la expansión de una sociedad la llevó a penetrar en regiones ya habitadas y, en consecuencia, a enfrentar a otras comunidades dispuestas a defenderse. Allí, la lucha por los recursos y el establecimiento de fronteras son los procesos que esperamos encontrar y que caracterizan la historia colonial de amplias regiones de las Américas. Nuestro análisis tomará como línea de base la noción de que el ambiente (y en particular los recursos naturales) jugaron un papel central en la evolución de las fronteras interétnicas en nuestro continente, porque cuando los europeos se expandían en busca de recursos, la mayoría de las sociedades nativas respondieron protegiendo su derecho a mantener el control sobre esos territorios. Proponemos como ejemplo la frontera en Arauco, en el sur de Chile a principios del siglo XVII, utilizando un modelo teórico que incluye la esfera demográfica, la esfera de los recursos y la esfera del conocimiento ${ }^{3}$. Esta última incluye un amplio campo de nociones culturales y de valores, tanto referidos a la naturaleza como a quiénes son los miembros de la otra sociedad y qué derechos tienen. Las tres esferas interactúan en un campo de fuerzas que, en el caso de la frontera colonial, estaba determinado por las decisiones imperiales que en su mayoría, eran decisiones estratégicas. Antes de analizar Arauco con esta propuesta teórica, comencemos por revisar las categorías y los conceptos que con mayor frecuencia aparecen en los estudios sobre las fronteras interétnicas en las Américas.

\section{Los estudios sobre las fronteras coloniales en las Américas}

El término "frontera" habitualmente implica que se aísla a una sociedad de la otra, aunque en realidad los contactos comerciales y el mestizaje en las zonas de frontera son más la norma que la excepción. Una definición de frontera como separación, sin embargo, deja resultados dudosos en cuanto a la especificidad del concepto. Así, el concepto de frontera, entendido como separación de las diferencias, ha permitido que se estudien demasiados tipos de "fronteras" en las ciencias sociales y como resultado tenemos fronteras geográficas, políticas, culturales, económicas, lingüísticas, étnicas, raciales, hasta incluso las fronteras de género y sexuales. El concepto de frontera es usado a veces como metáfora, a veces como concreción geográfica, a veces como sinónimo de un límite y a veces como espacio de hibridación. Tal variedad de fronteras alimenta las sospechas y los interrogantes, porque al ser tantas y tan diferentes a primera vista, ¿cómo puede ser que el mismo término "frontera" pueda describir un fenómeno tan polivalente? En suma, la expansión del concepto le ha hecho perder especificidad, aunque en su defensa, podemos argumentar que se ha ganado en riqueza. Y se sabe que lo que se gana en expansión se pierde en profundidad y, sobre todo, en especificidad.

Otras preguntas también resultan importantes, aunque difíciles de responder. ¿Pueden las fuentes para cada tipo de frontera tolerar el mismo tratamiento metodológico? ¿Han sido las fronteras coloniales de la forma en que las concebimos hoy? Y la pregunta que es a mi juicio la más inquietante de todas desde el punto de vista de la práctica historiográfica: ¿cómo vivía

\footnotetext{
${ }^{3}$ Utilizo las notaciones geográficas actuales de Chile o Argentina para facilitarle la ubicación al lector. Estos espacios geográficos en el siglo XVII pertenecían al sur del virreinato del Perú.
} 
aquella gente sus fronteras? En este sentido, me refiero a que existen dificultades planteadas por las fuentes; que hay vacíos que debemos llenar con más intuición que con indicadores documentales ${ }^{4}$.

Los esfuerzos por ordenar y clasificar las distintas fronteras son de larga data. Es decir, la preocupación por definir las fronteras es de todo, menos nueva. En 1907 Lord Curzon, virrey de India, estableció una gran diferencia entre las fronteras de "separación" y las fronteras "de contacto" . Desde entonces, se han descripto tres tipos principales de fronteras en la historia:

1. Inestables: que son las modificadas por motivos políticos, militares y/o diplomáticos;

2. Cerradas: que están destinadas a mantener separadas y sin contacto a dos sociedades en fuerte oposición; $y$

3. Expansivas: que es el modo que describe a casi todas las fronteras coloniales de las Américas ${ }^{6}$.

La frontera expansiva está relacionada con el imperialismo, porque tarde o temprano la expansión imperial encontrará sus límites, ya sean límites establecidos por factores externos o por factores internos, como señalamos. Los factores internos incluyen la disponibilidad de recursos materiales y humanos necesarios para llevar adelante tal expansión, mientras que los factores externos son casi siempre dificultades de la geografía. Más a menudo, y especialmente en el caso de las fronteras coloniales en América Latina, es el enfrentamiento entre la sociedad nativa y la europea lo que llevó al establecimiento de una frontera, algunas de ellas tempranamente militarizadas como fue el caso de la frontera con los chichimecas en el norte de México y la frontera con los araucanos en el sur de Chile.

En general, el concepto de la frontera expansiva tiene una dificultad importante tal como se lo usa en los estudios sociales. Primero, porque es un concepto que tiende a adoptar la perspectiva del conquistador y en esto hay una relación directa con las fuentes, ya que a menudo la utilización de tal perspectiva se debe a que solamente tenemos las fuentes de documentación producidas por los europeos. Por lo tanto, poco puede extrañar que este tipo de frontera nos provea de una explicación unilateral. Si pudiésemos tomar el punto de vista de los nativos, por ejemplo, la frontera colonial no se expandía, sino más bien lo contrario. En otras palabras, desde la perspectiva de los nativos, la frontera iba retrocediendo, porque era incapaz de detener a los invasores. Los nativos solamente podían ver a esa frontera como condenada a ir siendo erosionada por los blancos, hasta desaparecer. Y con su desaparición, desaparecería también la misma sociedad indígena ya que la tierra y sus recursos cambiarían de manos. En pocas palabras, la frontera se expandía solamente para los europeos.

\footnotetext{
${ }^{4}$ Hacemos referencia acá a la necesidad de diferenciar (pero a su vez complementar) la perspectiva émic (cómo es algo para los habitantes de una cultura) y la perspectiva étic (cómo es algo en una cultura para el investigador).

5 J.R.V. Prescott, Boundaries and Frontiers (Londres: Croom Helm, 1978).

${ }^{6}$ Daniel Power y Naomi Standen, eds., Frontiers in Question. Eurasian Borderlands, 700-1700 (Londres: McMillian, 1999).
} 
Otra dificultad de este concepto de frontera, pero en la escritura, es que la narración de la historia de las fronteras suele volverse teleológica, es decir, la frontera aparece siempre como provisional, como que avanza hacia un proceso en el que, finalmente, dejará de existir. Esta ha sido una de las características más llamativas de la historiografía tradicional que mostraba la formación del Estado nacional como un proceso de creciente integración territorial (y por lo tanto, de eliminación de las fronteras internas y de determinación de los límites con otros países) $^{7}$. Hay sin duda una clara contaminación ideológica en este procedimiento de narrar, por una parte y por otra parte, existe el punto de vista de que se conoce el resultado final de ese proceso. De este modo, al conocer de antemano la desaparición de una frontera, se procede metodológicamente en una secuencia que va del efecto a la causa. Si bien epistemológicamente no hay problemas en seguir ese procedimiento, su crítica más bien radica en que se trata de algo que puede ser éticamente argumentable, porque elimina en el recorrido gran parte de las contradicciones y de los sufrimientos de quienes serán presentados como finalmente integrados a la sociedad dominante y como finalmente miembros de la "civilización" y del "Estado nacional".

Este es en gran medida el caso de la frontera entre los nativos y los blancos en la región fronteriza de la Patagonia argentina en las últimas décadas del siglo XIX. En la historiografía argentina, la palabra "frontera" evoca una irrenunciable expansión del país para incorporar esa zona al Estado nacional. La Patagonia es así presentada como un área destinada desde el periodo español a ser ocupada por los hombres blancos y civilizados, aunque esto conllevase como "recompensa" por sus servicios la directa apropiación de las tierras y de los recursos que pertenecían a las tribus locales. Todas estas acciones desde el Estado nacional se hacían, por supuesto, sin juicio sobre la legitimidad (¡ni hablar de justicia!) del acto de apropiación que seguía (e impulsaba) a la expansión. Sin embargo, la campaña militar de 1879 comandada por el general Julio Argentino Roca se llamó "Campaña al desierto" que es un rótulo que mejor que nada muestra el total desprecio por la realidad de que esa zona estaba ocupada por tribus que poseían la tierra y habían controlado sus recursos desde tiempos inmemoriales. Más aun, la expansión en territorios que aún hoy son de los más fértiles de Argentina, difícilmente cuadre dentro de aquella definición de "desierto". Paradójicamente sin embargo, el rótulo incluso

\footnotetext{
${ }^{7}$ Para un examen más completo de esta tendencia historiográfica en los análisis sobre el papel de las campañas militares, las fronteras internas y las externas en Argentina, ver Oscar Oszlack, La formación del estado argentino (Buenos Aires: Belgrano, 1985). Otro enfoque teórico reciente ha sido aportado por Alejandro Grimson, comp., Fronteras nacionales e identidades (Buenos Aires: Ciccus, 2000). Los estudios históricos considerados actualmente clásicos parten de las obras de Tulio Halperín Donghi, especialmente su Proyecto y construcción de una nación, Argentina 1846-1916 (Caracas: Biblioteca Ayacucho, 1980) y de Natalio Botana, El orden conservador. La política argentina entre 1880 y 1916 (Buenos Aires: Sudamericana, 1977). Una obra colectiva reciente ha rescatado y revisado las tendencias historiográficas dentro de las cuales se inscriben las reconstrucciones de los procesos relativos a las fronteras: Hilda Sábato y Alberto Lettieri, comp., La vida política en la Argentina del siglo XIX. Armas, votos y voces (Buenos Aires: Fondo de Cultura Económica, 2003) y existe un espíritu similar para el caso de las fronteras norteamericanas en el tomo colectivo de Christine Daniels y Michael Kennedy, ed., Negotiated Empires. Centers and Peripheries in the Americas, 1500-1820 (Nueva York: Routledge, 2002).
} 
contradecía la descripción de las propias autoridades argentinas de que estas tierras serían aptas para la agricultura y la ganadería ${ }^{8}$.

Hay otras categorías y conceptos que merecen un comentario. Los términos "límite" y "bordes", por ejemplo, también se utilizan con frecuencia como equivalentes a "frontera" en los estudios sociales, quizás porque todos indican una separación geográfica, algún grado de oposición y diferentes mezclas raciales y culturales. Pero también acá hay dificultades para separar los conceptos y categorías en forma nítida. Los geógrafos políticos han distinguido entre un límite/borde y una frontera. Para ellos el primer concepto se refiere a una división linear y precisa, dentro de un marco político; mientras que el segundo tiene más las características de un espacio amplio, de una zona, y así expresa características que son más sociales y comportamentales que únicamente políticas y administrativas ${ }^{9}$. El límite es una división linear a partir de donde y hasta donde un sistema político ejerce su poder y su jurisdicción. Estas acciones de soberanía política se hacen notar a través del establecimiento de construcciones y puesta de señales que varían de acuerdo a espacio y tiempo, desde las fortificaciones militares y misiones en la época colonial, hasta oficinas de migraciones, alambradas o murallas y patrullas con sofisticado armamento que caracterizan a algunas fronteras de la actualidad. Por su parte, una frontera es vista como una zona, aunque sus características deriven de la presencia del límite. La frontera aparece como un escenario en el cual los grupos diferentes y en oposición modelan la identidad colectiva. En su trabajo pionero, el antropólogo Frederick Barth demostró convincentemente que el surgimiento de las fronteras étnicas -como las que hay en las Américas durante la etapa colonial- adquieren sus características y evolucionan conforme al impacto que ejerce sobre ellas el otro grupo social. Por esto, ese otro social determina la existencia de la frontera étnica con su amplio rango de comportamientos, desde la pacífica tolerancia hasta el brutal genocidio ${ }^{10}$.

En los Estados Unidos, la palabra frontera aparece cargada desde múltiples lados debido a la influencia que dejó Frederick Jackson Turner (1861-1932). A fines del siglo XIX Turner llamó la atención sobre el rol que la frontera (entendida como un espacio abierto y disponible) había tenido en la historia de los Estados Unidos. Turner no fue el primero, pero fue el más influyente de todos al proclamar su tesis de que la frontera expansiva había impulsado el rumbo de la historia y forjado la mentalidad del país. Propuesta en 1889, la tesis de Turner afirmaba que la frontera en Estados Unidos fue mucho más que una condición geográfica inerte. La frontera fue la fuerza que modeló la sociedad americana, que puso en marcha y que mantuvo la maquinaria productiva para una permanente expansión. Y más todavía, la frontera había sido el factor clave que le dio al país sus valores más permanentes y su mentalidad colectiva. Un Turner cuyo estilo

\footnotetext{
${ }^{8}$ La bibliografía sobre Julio Argentino Roca, sus acciones militares y políticas, junto con las ideas de la Generación del Ochenta es muy extensa. Estudios clásicos siguen siendo los de Tulio Halperín Donghi, en particular, Proyecto y construcción.

${ }^{9}$ Peter Sahlins, Boundaries: The Making of the France and Spain in the Pyrenees (Berkeley: University of California Press, 1989), 4.

${ }^{10}$ Frederick Barth, The Anthropology of Ethnicity (The Hague: Spinhuis, 1994) y Ethnic Groups and boundaries: the social organization of culture difference (Boston: Little Brown, 1990).
} 
es a veces demasiado declarativo impulsó a lo largo del siglo $\mathrm{XX}$, una tesis que ha sido interpretada, analizada, criticada y descalificada de las más diversas formas ${ }^{11}$. En el proceso, está presente en los trabajos sobre frontera, haciendo que los historiadores y las historiadoras siempre procedan a disculparse por la utilización del término, o procuren evitarlo completamente. Tomar distancia de Turner, sin embargo, ha sido una forma de seguirlo invocando, por lo que Robert Burns ha afirmado que Turner se ha convertido en un vampiro que, aunque matado innumerables veces con la estaca de madera de su misma tesis, está todavía vivo y acechándonos ${ }^{12}$.

A pesar de la controversia, tiene cierta utilidad volver a su pensamiento original. En cierto sentido, Turner tuvo razón cuando reconstruyó el pasado de los Estados Unidos dentro de un esquema que procuraba que la Escuela Alemana de Historia (en la cual él había sido educado) se dejara de lado. Turner proponía entonces que la visión de las fronteras establecidas en Europa por las guerras y por la diplomacia era desacertada para el caso de las fronteras en los Estados Unidos. Su esfuerzo por separar la historiografía nacional de los esquemas interpretativos vigentes en la historiografía de Europa es, sin duda, meritorio. Lo lamentable es que para hacerlo recurrió a lo que varios consideran una visión heroica y difícil de digerir de lo que fue la expansión de los Estados Unidos en el hemisferio norte. Por ejemplo, Turner nos dejó esta hiperbólica descripción de la influencia de la frontera en los Estados Unidos:

El resultado es que el intelecto americano le debe a la frontera sus salientes características. La dureza y la fuerza combinadas con la precisión y la habilidad inquisitiva, los giros mentales de la invención práctica, la rapidez para encontrar soluciones, lo que hábilmente puede materializarse, faltándole el toque artístico pero poderoso para alcanzar grandes metas, la incansable energía, el dominante individualismo, trabajando para bien o para mal, y la exuberancia que acompaña la libertad, todas éstas son las huellas de la libertad, o las huellas de cualquier otra cosa que allí estaba, pero porque estaba la frontera ${ }^{13}$.

Más allá de la controversia, si consideramos su propuesta como un programa de investigación, los historiadores podemos evaluar el impacto que tuvo una frontera durante el período colonial sobre las pequeñas comunidades periféricas que debían protegerse o que debían sostener con las

\footnotetext{
${ }^{11}$ Existe una vasta literatura sobre Turner tanto en inglés como en español. A título de ejemplo solamente cito algunos títulos en inglés: Frederick J. Turner, Frontier and Section. Selected Essays of Frederick Jackson Turner (Englewood Cliffs: Prentice Hall, 1961); John Faragher, Re-reading Frederick Jackson Turner. The significance of the Frontier in American History and other Essays (Nueva York: Holt, 1994); Wilbur Jacobs, On Turner's Trail (Lawrence: University Press of Kansas, 1994); Gregory Nobles, American Frontiers (Nueva York: Hill \& Wang, 1997); y Kervin Lee Klein, Frontiers of Historical Imagination. Narrating the European Conquest of North America, 1890-1990 (Berkeley: University of California Press, 1999).

${ }^{12}$ Robert Burns, "The Significance of the Frontier in the Middle Ages", en Robert Bartlett y Angus Mackay, eds., Medieval Frontier Societies (Oxford: Clarendon Press, 1996): 307-39.

${ }^{13}$ Frederick J. Turner, "The significance of the Frontier in American History" (Proceedings, 1893), citado por Klein, Frontiers of Historical.
} 
armas el avance sobre territorios de nativos. En este sentido, estas comunidades de frontera desarrollaban una estructura particular, tanto en lo social como en lo económico ${ }^{14}$.

Pero en cuanto a las consecuencias ideológicas, la visión de Turner es indefendible, aunque en su descargo hay que señalar que abreva de una ideología muy difundida en el siglo XIX. Por una parte, está la idea de que una sociedad se expande en busca de sus fronteras "naturales" (noción implícita en Turner) y que contiene elementos incluso cuestionables desde el punto de vista de los mismos hechos. Para empezar, no existen fronteras "naturales" o expansiones que cumplan con objetivos de supuestos "destinos" (la ideología del Destino Manifiesto en Estados Unidos ha justificado las guerras expansivas). Ya se ha demostrado ampliamente que se acepta la presencia de un río o de una cadena montañosa en tanto que ayuda a fijar visiblemente un límite que ha sido convenido previamente, a veces después de largas guerras o después de arduas gestiones diplomáticas. El río o la cadena montañosa solamente son selecciones convenientes, pero esas presencias por sí solas jamás explicarían los procesos sociales asociados al establecimiento y a la evolución de una frontera determinada.

Otro aspecto a tener en cuenta es que las fronteras coloniales en América del Norte surgen de mezclas interétnicas, mestizajes y fragmentaciones dentro de las mismas sociedades tribales (el caso de los métis de Canadá ha sido, en este sentido, el más paradigmático). Aparecen también instituciones como The Hudson Bay Company donde las relaciones interétnicas fueron habitualmente pacíficas, favoreciendo así la permanencia del comercio que les era mutuamente favorable. El contacto comercial permitió que los europeos dominaran las lenguas nativas en los puestos de intercambio, o porque ellos habían sido cautivos, o porque pronto la población del lugar se caracterizaba por ser mestiza. Un cuadro semejante se repite en varias de las fronteras en América del Sur. En el ámbito de las fuentes, en estas fronteras suelen quedar relatos de colonos mestizos, oficiales y misioneros que abren una ventana a los avatares de la vida cotidiana en la frontera, entendida ésta como un espacio social con escenas bastante poco heroicas y con una vida cotidiana bastante penosa ${ }^{15}$.

Por otra parte, durante la colonia las fronteras entendidas como límites fueron el resultado de guerras y pactos diplomáticos ejecutados entre las potencias europeas, porque la metrópolis prefirió sacrificar porciones de su territorio en este continente, con tal de preservar territorio en Europa. De esta forma, aunque las guerras eran entre potencias europeas y en territorios europeos, las transformaciones en los límites o los cambios en las fronteras ocurrían en territorio americano. Esta estrategia imperial ocasionó fronteras mercuriales que se modificaban al calor o el frío de las relaciones entre las potencias europeas. Esto es en parte lo que denominamos el campo de fuerzas en el cual interactúan las esferas locales de la población, los

\footnotetext{
${ }^{14} \mathrm{He}$ explicado estas nociones en artículo anteriores. En relación con las fronteras coloniales internacionales, ver Gascón, "The Military of Santo Domingo" y en relación a fronteras interétnicas, ver mis artículos "La transición de periferia a frontera: Mendoza en el siglo XVII", Revista Andes, no. 12 (2001):175-199, y "Frontier Societies: A View from the Southern Frontier of the Indies", en Working Paper (Cambridge: Harvard University, 2002).

${ }^{15}$ Para un análisis del cautiverio tanto en América del Norte como en América del Sur, ver Fernando Operé, Historia de las fronteras: el cautiverio en la América hispánica (Buenos Aires: FCE, 2001).
} 
recursos y el conocimiento. Las fronteras en las Américas, en efecto, deben relacionarse con el campo de las fuerzas imperiales, es decir, con las decisiones que, aunque tomadas en las metrópolis, afectaban la evolución local. Además, desde un punto de vista estrictamente geográfico, las fronteras coloniales estaban localizadas en regiones periféricas, con escasos recursos y bastante despobladas; pero desde el punto de vista de la estrategia defensiva o militar, para la corona algunas fronteras eran de todo menos periféricas. En otras palabras, algunas áreas eran vitales no tanto por sus recursos o por su densidad demográfica, sino porque eran regiones que podrían servir de plataforma para que alguna otra potencia extranjera lanzara un ataque sobre las áreas más vitales y ricas del imperio. Desde este punto de vista estratégico, entonces, tenía sentido para la metrópolis destinar recursos para mantener ciertas periferias controladas. Aun estando estas colonias en la periferia del imperio no fueron colonias periféricas en el sentido estricto del término, ya que recibían recursos y atención especial por parte de la corona. Precisamente se trata del caso del sur de Chile a principios del siglo XVII.

Hemos dicho que queremos iluminar la vida de las fronteras a partir de un modelo que considere las interrelaciones de tres esferas: la población, los recursos y el conocimiento. Estas tres esferas se relacionan dentro del campo de fuerzas determinado por las decisiones imperiales, fuesen éstas decisiones estratégicas económicas o de cualquier tipo. Comencemos con la esfera de la población, que ha sido siempre un elemento clave en la comprensión de la evolución de las sociedades en el pasado, y en el caso especial de las Américas, la corriente cuantitativa y demográfica ha tenido una poderosa influencia con la llamada Escuela de Berkeley ${ }^{16}$.

La cantidad de gente explica actividades relacionadas con la expansión, las formas de producción, las guerras, las pestes y el comercio, entre otras. Por ejemplo, las catástrofes demográficas tales como la Peste Negra en Europa a finales de la Edad Media han sido vistas como una de las causas de la expansión de los países ibéricos en busca de esclavos para revertir la falta de mano de obra que paralizaba la producción agrícola y el comercio en vastas regiones del continente ${ }^{17}$. Al mismo tiempo, esa pregunta sobre "cuánta gente" como explicación nos lleva a asociaciones con el tamaño de los mercados consumidores o con el tamaño de las

\footnotetext{
${ }^{16}$ Woodrow W. Borah y Sherburne F. Cook, The Aboriginal Population of Central Mexico on the Eve of the Spanish Conquest (Berkeley: University of California Press, 1963); Woodrow W. Borah, La demografia histórica de la América Latina: fuentes, técnicas, controversias, resultados (Bogotá: Universidad Nacional de Colombia, 1972); Historia y población en México: siglos XVI-XIX (México, D.F.: Centro de Estudios Históricos, Colegio de México, 1994); Magnus Mörner, Evolución demográfica de Hispanoamérica durante el periodo colonial (Stockholm: Institute of Latin American Studies, 1979); Noble D. Cook, Demographic collapse, Indian Peru, 1520-1620 (Cambridge, Nueva York: Cambridge University Press, 1981); Born to die: disease and New World conquest, 14921650 (Cambridge; New York: Cambridge University Press, 1998); David J. Robinson, ed., Studies in Spanish American population history (Boulder: Westview Press, 1981); Noble D. Cook y W. George Lovell, eds., Secret judgments of God: Old World disease in colonial Spanish America (Norman: University of Oklahoma Press, 1991).

${ }^{17}$ David Herlihay, The Black Death and the Transformation of the West (Cambridge: Harvard University Press, 1997). Ferdinand Braudel y Pierre Chaunu avanzaron en la utilización de este tipo de enfoque; para un análisis completo de su propuesta, ver Immanuel Wallerstein, The Modern World System, (Nueva York: Academic Press, 1974), vol. 1; ver también Sheldon Watts, Epidemics and History: Disease, Power and Imperialism (New Haven: Yale University Press, 1997).
} 
sociedades productoras de algún bien ¿Cuánta gente trabaja? ¿Cuánta gente consume? ¿Cuánta gente es afectada por la falta de un producto? Después que se pierde una cosecha en sociedades del Antiguo Régimen, ¿cuánta gente dejaba de consumir? ¿Cuántos dejaban de producir? ¿Y a cuántos a su vez esto perjudicaba, o beneficiaba llegado el caso?

Los desbalances demográficos cambiaban repentinamente la relación con los recursos naturales, de modo que se producía una interacción entre las esferas de la población y de los recursos. Además, la esfera del conocimiento también se veía afectada y, a su vez, afectaba a las otras dos esferas. Por ejemplo, las necesidades de una sociedad generan demandas por mejores técnicas para solucionar los problemas de escasez o de deficiencias en la producción o en la distribución de un determinado recurso por falta de mano de obra. La esfera de los recursos entonces está fuertemente articulada con la esfera demográfica. Las dos preguntas de cuánta gente y cuántos recursos nos permiten reconstruir casi todos los ámbitos de la historia ambiental. Pero más interesante es que esas preguntas también explican buena parte de la historia política, en el sentido de que políticamente se resuelven las preguntas de quién se queda con el derecho de apropiarse de qué recursos. Y en este nivel, la pregunta se puede separar en dos vertientes ya que, por una parte, habrá conflictos internos o lucha de clases; y por otra parte, generará tensiones internacionales, porque los recursos no se encuentran igualmente distribuidos dentro de una sociedad o dentro del planeta. Es decir, la distribución de los recursos es desigual tanto socialmente como geográficamente. Por eso, su apropiación y distribución en una sociedad, o entre dos o más sociedades, está atravesada de conflictos que se discuten políticamente para darles una solución pacífica o bélica.

Esta esfera cambia, es decir, el valor de los recursos es cambiante. Su valor depende tanto de la esfera demográfica (la cantidad de gente que necesite o quiera ese recurso) como de la esfera del conocimiento. Una de las formas de interacción de las tres esferas es que puede haber aumento de la demanda de un recurso como respuesta al aumento de la población, pero puede que un desarrollo en el conocimiento (puede ser un desarrollo técnico) haga que ese recurso no se convierta en un bien escaso o inaccesible.

Otra de las formas de interacción entre las esferas de población y de recursos es el rol de las enfermedades y de las catástrofes naturales. Las enfermedades han recibido atención como parte de las explicaciones históricas ${ }^{18}$. Pero las catástrofes han sido a menudo ignoradas $\mathrm{o}$ consideradas como poco menos que anécdotas curiosas. Sin embargo, catástrofes masivas como terremotos alteraban drásticamente la relación entre los recursos y la gente. Fueron mayoritarias las áreas en nuestra América colonial que tenían pocas posibilidades de sobreponerse a la pérdida que podía ocasionar una erupción volcánica, por ejemplo, al arruinar sus cultivos o deteriorar los ríos y lagunas que proveían de agua dulce y de alimentos. Ejemplificaremos esta afirmación con la erupción del Villarica en 1640, que llevó a los rebeldes araucanos a parlamentar con los españoles en Quillín en $1641^{19}$. La historiografía chilena tradicional, sin

\footnotetext{
${ }^{18}$ Ver por ejemplo Frederick Cartwright, Disease and History (Nueva York: Barnes and Noble, 1991) y Alfred Crosby, Ecological Imperialism (Cambridge: University of Cambridge Press, 1999).

${ }^{19}$ La expresión "araucanos rebeldes" se emplea para diferenciarlos de los indios amigos, aliados de los españoles.
} 
embargo, siempre ha presentado este parlamento como obra diplomática del gobernador. Tal explicación devela al mismo tiempo dos defectos de nuestra producción historiográfica. Por un lado, el extremo eurocentrismo que hace que siempre sean los blancos quienes tomaron las acciones decisivas y pertinentes. Y por otro lado, el homocentrismo, ya que siempre son los seres humanos los que marcan el curso de los acontecimientos. La naturaleza es mostrada así exclusivamente como un escenario. Nunca actúa. Y por su parte, los nativos solamente "reaccionan"; es decir, pocas veces son los actores o los que ponen voluntaria y conscientemente en marcha un proceso de cambio histórico.

En cuanto a la esfera del conocimiento, ésta intercepta a las otras dos esferas. El conocimiento es en gran medida lo que determina el tipo y la evolución de las relaciones entre la esfera de la gente y la esfera de los recursos. El conocimiento debe ser entendido como un rótulo amplio que incluye conceptos, ideas, valores tanto sobre la gente como sobre los recursos. Incluye así la cosmovisión, las ideas religiosas y los conceptos que tenemos sobre numerosos ámbitos de la realidad, sobre cómo producir mejor algo o sobre cómo debemos asignar bienes y servicios. El conocimiento también involucra al sistema legal ya que las leyes se basan en ciertos conceptos y categorías sobre la naturaleza de otros seres humanos, sobre sus capacidades y sus derechos, y sobre las explicaciones de qué es lo "justo" en nuestra manera de relacionarnos con ellos. Por ejemplo, el conocimiento basado en las ideas de Aristóteles y de Santo Tomás a principios de la Edad Moderna sobre la naturaleza de los hombres otorgaba los argumentos filosóficos y teológicos que los europeos necesitaban para justificar que la esclavitud era justa, y en el caso específico de Hispanoamérica, para justificar la legitimidad de la conquista, de la guerra y de la extracción del trabajo indígena a través de la encomienda. Cambios en la esfera del conocimiento fueron los que determinaron también los cambios en los sistemas legales y, por lo tanto, en las relaciones entre los europeos, los negros y los nativos.

De manera similar también, el conocimiento acerca de la naturaleza nos brinda un marco legal que será el que finalmente controle el uso y la distribución de cada recurso natural, desde la tierra al agua y desde los minerales a los animales. La ciencia y la tecnología son tal vez hoy los principales ingredientes cuando pensamos en la esfera del conocimiento, pero siempre hemos basado nuestras acciones en un determinado conocimiento, bien sea un conocimiento científico o un conocimiento más general, tradicional, o basado en concepciones religiosas o tradiciones culturales. En cualquiera de los casos, sigue siendo una forma de conocimiento la que guía las conductas y las formas de relacionarnos con el ambiente, con miembros de nuestra sociedad y con los desconocidos.

Estas tres esferas interactúan, como señalamos, permanentemente. Sin embargo, no tienen el mismo nivel de importancia o producen el mismo impacto siempre. En algunas ocasiones, es la esfera demográfica la que adquiere una posición relevante, pero en otras situaciones, es la esfera del conocimiento la que más afecta la relación entre los recursos y la gente. Veamos ahora este modelo en el caso de la frontera en Arauco. 


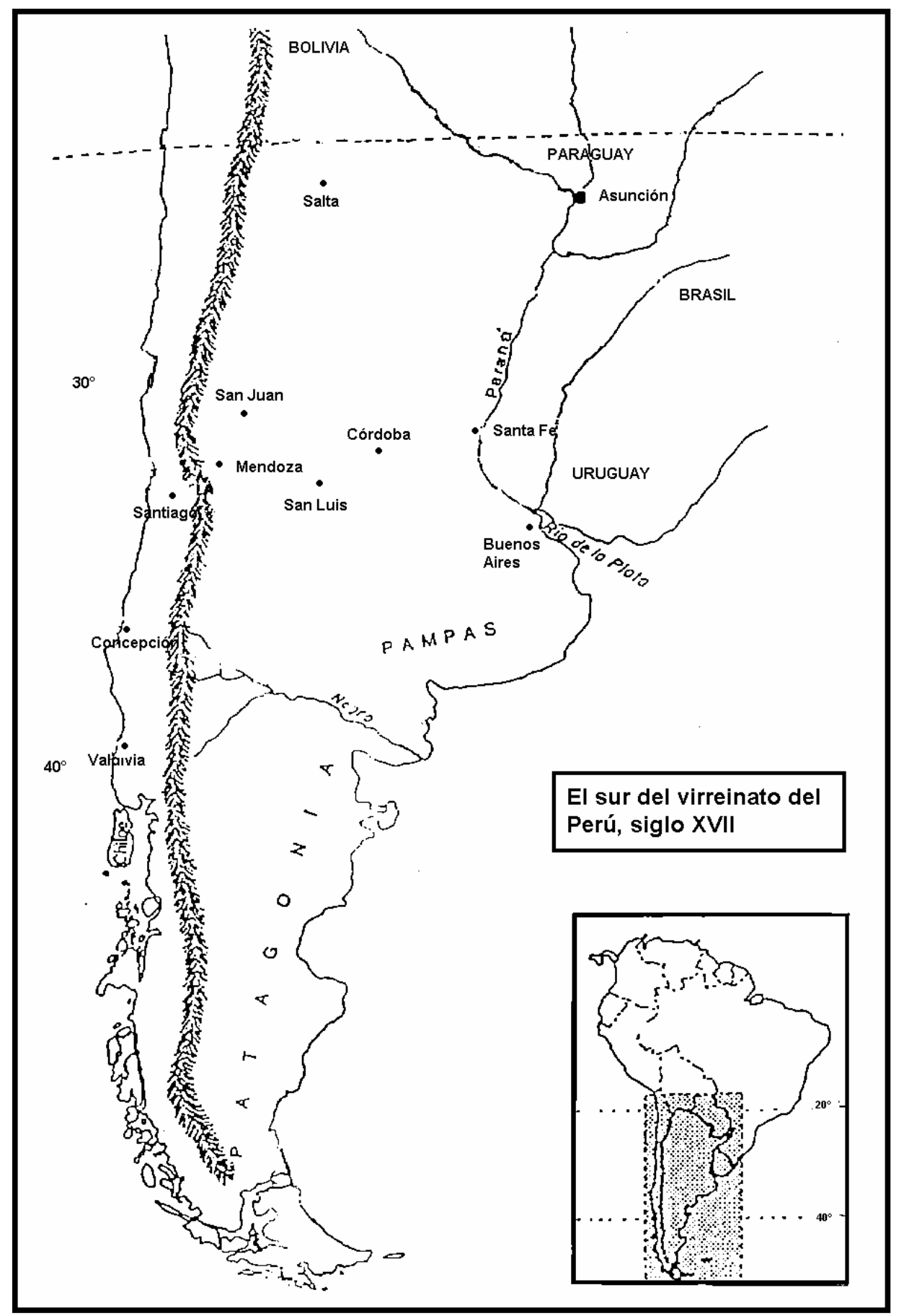

Mapa 1. El sur del Virreinato del Perú. 


\section{El caso de la frontera en Arauco}

Durante la segunda parte del siglo XVI los españoles pudieron penetrar hasta el sur de Chile, en la zona conocida como la Araucanía. Pero la rebelión de los nativos en 1598-99 revirtió la situación en forma dramática, impidiendo la consolidación de la conquista y la colonización. En un lapso de pocos meses, los españoles debieron abandonar el área apresuradamente y refugiarse al norte del río Bio-Bio. La zona pudo bien haber quedado abandonada, pero en cambio, la corona decidió enviar un ejército de unas 2.000 plazas que se pagarían con dinero de las cajas peruanas. La decisión era excepcional puesto que la corona prefería mantener a sus colonias sin ejércitos y encomendar la defensa a los encomenderos. Además, para la misma fecha en que se decide la militarización de Chile, se acababa de imponer la política de pacificación y de paz por compra en la otra frontera viva del imperio: la frontera con los chichimecas. La decisión imperial de militarizar la frontera araucana generó un campo de fuerzas diferente del que existía en el sur de Chile hasta finales del siglo XVI, provocando así cambios bruscos en la esfera de los recursos y de la población.

¿Por qué España tomó tal decisión? Por una parte, la esfera demográfica tuvo su peso, porque, como en todas las periferias del imperio, Arauco contaba con muy pocos españoles y encomendarles la defensa había demostrado ser muy poco efectivo. Por otra parte, la esfera del conocimiento se impuso en el sentido de que España temía no tanto a una rebelión de indígenas sino a los posibles ataques del enemigo holandés. Estratégicamente, el sur de Chile era la parada obligada para cualquier expedición que, organizada en América del Sur, se propusiese atacar el corazón del imperio, es decir, atacar a Lima o Potosí. Perdidas esas colonias, recuperarlas se volvería casi imposible, empezando por la falta de población local para organizar la expedición. A principios del siglo XVII, una autoridad real describió a Chile como "ocho ciudades tan pobres como despobladas". Su principal ciudad, Santiago, era en efecto un conjunto de unas 200 casas, Concepción le seguía con sus 76, Mendoza sumaba 32 viviendas y San Luis tenía $10^{20}$.

En este contexto de falta de habitantes, se entiende incluso mejor el impacto que produjo la instalación de un ejército de 2.000 soldados, lo cual a su vez creaba un interesante mercado para armas de fuego, municiones, ganado, caballos y alimentos. Desafortunadamente, sin embargo, el Valle Central de Chile es una estrecha franja entre la cordillera de los Andes y el Pacífico. Hacia el norte el clima se va volviendo más árido hasta culminar en el desierto más extremo del planeta (Atacama). De este modo, los recursos naturales que ya eran escasos, se volvieron más escasos todavía cuando se perdió Arauco, la región más fértil del país.

La decisión de la corona de establecer un ejército profesional suponía a su vez consideraciones de logística de cierta envergadura. Cómo alimentar a las tropas era (y sigue siendo) un límite en el tamaño de los ejércitos y en los ritmos de las campañas. Las líneas de abastecimiento fueron en el siglo XVII un motivo central de preocupación militar en Europa, donde algunos ejércitos

\footnotetext{
${ }^{20}$ La provincia de Cuyo en actual territorio argentino (Mendoza, San Juan y San Luis) pertenecía al Reino de Chile en el siglo XVII. Archivo Nacional de Chile, Fondo Claudio Gay, documento 22, expediente 23, volumen 14.
} 
llegaban a contabilizar 30.000 hombres, aunque debemos contextualizar esta información. ¿A qué se denominaba un "ejército" a principios de los tiempos modernos? Algunos dibujos muestran que lo que las fuentes denominan "ejércitos" eran más bien un conjunto de hombres, acompañados incluso por sus mujeres y acarreando su alimento. No tenemos razón alguna para pensar que los ejércitos en América estaban en mejores condiciones. De acuerdo con esos grabados y dibujos, la mayoría iba a pie y armados solamente con lanzas. Con hambre crónica, su presencia para los poblados de campesinos era sinónimo de saqueo y destrucción ${ }^{21}$.

En las Américas, una situación similar de ejércitos sin suficientes alimentos había funcionado a favor de los nativos, ya que una de sus estrategias para contener sus avances o alejarlos fue privarlos de alimentos. Es más, cuando los poblados de indios sabían de la proximidad de tropas europeas en la fase de la conquista, una de sus principales "armas" de lucha consistió en abandonar los pueblos tras haber envenenado la comida, en conocimiento de que los invasores primero comían y después saqueaban y destruían. Muchos europeos, por esto mismo, aprendieron rápidamente la lección de procurar contactos pacíficos, ya que la buena voluntad de los indígenas para auxiliarlos con la comida marcaba la diferencia entre sobrevivir o morir.

En gran medida, la disponibilidad y distribución de comida determinó el patrón de expansión y de asentamiento en este continente, a pesar de que los historiadores no siempre han considerado este hecho como parte de su explicación. Veamos un ejemplo significativo. Se trata de 1643, cuando los holandeses - tal como lo había temido la corona española a principios del siglo XVII- llegaron al sur de Chile e intentaron establecerse en Valdivia. Pero de acuerdo con el diario de la expedición, cuando murió su jefe Enrique Brouwer, la situación comenzó a deteriorarse por la falta de alimentos. Los araucanos a duras penas si les abastecían con unas pocas cabezas de ganado, esporádicamente y siempre a cambio de $\operatorname{armas}^{22}$.

No era un patrón nuevo de comportamiento de los indígenas locales. Hacia esa fecha, ya habían comprobado que el hambre era el peor enemigo de los europeos y, por esto mismo, su mejor aliado para combatirlos o para controlarlos. Preguntado en una oportunidad un jefe araucano sobre el porqué nunca había atacado al pequeño asentamiento de Angol para destruirlo, el indio se encogió de hombros y respondió que él no necesitaba actuar en tales casos porque de eso se encargaba el hambre y el aburrimiento; él solamente realizaba acciones menores como robarles los caballos a los españoles para que tuviesen todavía más penalidades para salir a proveerse de leña y alimentos ${ }^{23}$.

\footnotetext{
${ }^{21}$ Sobre los inconvenientes de los ejércitos a principios de la Edad Moderna en Europa, ver Andrew Cunningham y Ole P. Grell, The Four Horsemen of the Apocalypse. Religion, War, Famine and Death in Reformation Europe (Cambridge: Cambridge University Press, 2000).

22 "Nota bibliográfica sobre el viaje de Enrique Brouwer a Chile", en Colección de Historiadores de Chile, tomo 65 (Santiago de Chile: Universitaria, 1923): 121-226. Para un panorama cronológico, ver Héctor Ratto, Actividades marítimas en Patagonia durante los siglos XVII y XVIII (Buenos Aires: Kraft, 1930).

23 "Informe mandado levantar por el gobernador de Chile, Francisco López de Zúñiga, Marqués de Baides, sobre el estado en que encontró la Real Caja y almacenes del situado. Concepción, 20 de mayo de 1639”, Biblioteca Nacional de Chile, Sala Medina, Manuscritos, volumen 136, documento 2470, 5.
} 
España por su parte también sabía que la falta de comida en la zona sur de su imperio podía volverse en una aliada estratégica en caso de intentos de invasión. La Patagonia argentina, en efecto, se caracterizaba por su falta de agua dulce y de alimentos a lo largo de la costa. En el Estrecho de Magallanes había habido un intento fallido de establecimiento de colonias españolas en el siglo XVI y sus pocos sobrevivientes fueron finalmente rescatados de la muerte segura por un barco inglés. Desde entonces, la corona española desdeñó cualquier informe alarmista sobre holandeses o ingleses estableciéndose en el Estrecho de Magallanes. Por su propia experiencia, España sabía que todo establecimiento tan al sur debía depender de una línea de abastecimiento continua. De lo contrario, cualquier colonia tenía sus días contados. Pero si el establecimiento era en Arauco, las condiciones cambiaban dramáticamente, en particular, si los indios locales comprometían su ayuda ${ }^{24}$.

La duda de la corona, por lo tanto, siempre era si los araucanos podían convertirse en aliados de sus enemigos y establecer así esa línea continua de abastecimiento que se necesitaba para la supervivencia. La sospecha de que los araucanos colaborarían con otros europeos, sin embargo, puede parecernos absurda, porque difícilmente los indígenas confiarían más en un europeo que en otro. Cuando los holandeses preguntaron sobre el oro de Valdivia, por ejemplo, los indígenas se alarmaron y apresuradamente contestaron que ya no trabajaban más esas minas de oro por el mal recuerdo que les traía la experiencia con los españoles, que los habían explotado tanto que los llevaron a levantarse contra ellos y expulsarlos de la zona. Los holandeses se apresuraron entonces a afirmar que en caso de volver, lo harían con esclavos negros para el trabajo de las minas. Pero el gobernador de Chile, el marqués de Baides, se encargó de esparcir ampliamente el rumor de que los holandeses únicamente querían apropiarse del oro de Valdivia y solamente por esta razón se habían desplazado hasta el sur de Chile y padecido tan grandes penurias durante la travesía ${ }^{25}$.

\footnotetext{
24 "Informe de don Juan de Henríquez al virrey del Perú. Concepción, 12 de marzo de 1635", Biblioteca Nacional de Chile, Sala Medina, Manuscritos, volumen 133, Documento 2416 y "Certificado de don Gaspar de Suazo y Villaroel, sargento mayor de la gobernación del Reino de Chile, sobre lo acordado en una junta de guerra para tratar la mejor manera de desalojar a los ingleses que han poblado el Estrecho de Magallanes”, Biblioteca Nacional, Sala Medina, Manuscritos, volumen 133, documento 2418.

25 "Copia de una carta del Marqués de Baides escrita a un religioso de la Compañía de Jesús, 20 de agosto de 1644 (progreso de la guerra y desembarco del holandés en Valdivia)", Biblioteca Nacional de Chile, Sala Medina, Manuscritos, volumen 137, documentos 2520, 430.
} 


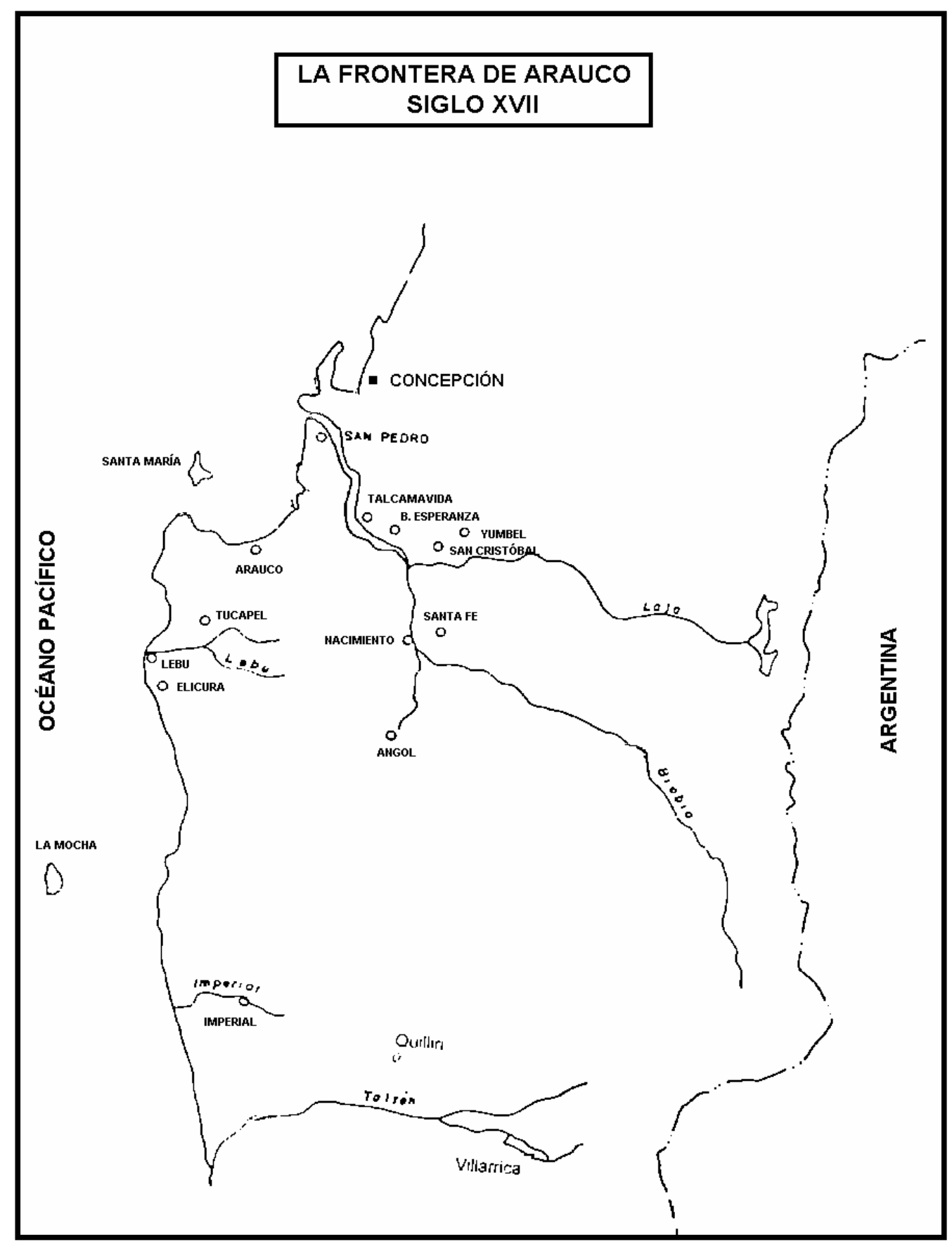

Mapa 2. La frontera en Arauco, siglo XVII. 
En relación también al tamaño del ejército, sus movimientos y transporte, los caballos fueron fundamentales durante la primera mitad del siglo XVII. Su disponibilidad limitó las acciones de las tropas en forma creciente. Unos pocos años después de la conquista, los araucanos ya habían aprendido a criar excelentes animales, con lo cual los españoles perdieron su superioridad en este aspecto. Pero la superioridad no era tanto en el campo de batalla porque las escaramuzas eran en zonas boscosas donde la infantería es más efectiva que la caballería. Al robarlos, lo que los indios hacían era limitar el movimiento y el abastecimiento de los españoles. A principios del siglo XVII, con la llegada del ejército profesional se debió encargar la compra de caballos en el lejano Paraguay, según Alonso de Sotomayor, debido al altísimo precio de los caballos en Chile $^{26}$. Pero toda la operación de la compra fue desastrosa ${ }^{27}$.

La reforma militar encarada por el gobernador Alonso de Rivera (1601-05) procuró que en las recién establecidas estancias rurales se criaran caballos aptos para el terreno montañoso y boscoso de Arauco. Sin embargo, es posible detectar en las fuentes que los caballos terminaron por convertirse en parte del problema que se buscaba solucionar. Y esto por dos motivos. Primero, porque los indígenas los robaban para paralizar así las campañas de los españoles en sus territorios, o para limitarles el radio de movimiento, ya que cada soldado necesitaba alrededor de seis animales para su transporte y para su carga de alimentos y elementos bélicos. Segundo, porque las campañas solamente se podían realizar en verano y para esto se necesitaba disponibilidad de pastos en las escasas rutas por las que las tropas podían transitar. Los nativos simplemente quemaban los pastos de los alrededores de esos caminos. Este dato debe verse como parte de la esfera del conocimiento, aunque en la esfera del conocimiento de los nativos. Nos interesa destacar que este dato indica que las campañas en Arauco eran entonces más determinadas por los comportamientos de los indígenas que por las decisiones de los gobernadores. Pero éstos casi nunca relataban tales maniobras de los indios que los habían reducido a la impotencia. Por el contrario, los gobernadores siempre presentaban informes triunfales y siempre describían a sus campañas como difíciles pero exitosas. En realidad, los araucanos rebeldes controlaban bastante bien la situación con ese dispositivo bastante simple de quemar los pastos que debían alimentar a caballos y al ganado vacuno que se arreaba para el alimento de las tropas españolas ${ }^{28}$.

La cifra de los animales desplazados durante estas campañas del ejército español en territorio araucano es significativa. Según las fuentes, el ejército español durante la primera mitad del

\footnotetext{
${ }^{26}$ Sobre el gobernador Alonso de Sotomayor y sus servicios, ver Francisco Caro de Torres, Relación de los servicios que hizo a su magestad del Rey don Felipe Segundo y Tercero, don Alonso de Sotomayor (Madrid: 1620); Miguel de Aguirre, Población de Baldivia (Lima: Julián Santos, 1647), 33; y Pedro Mariño de Lovera, "Crónica del Reino de Chile", en Biblioteca de Autores Españoles (Madrid: Atlas, 1960), 413.

${ }^{27}$ El enviado ni siquiera pudo llegar a Asunción de Paraguay debido a que el río Paraná estaba con crecida. En Santa Fe juntó 700 caballos, pero la mitad se le escaparon y los que finalmente llegaron a la frontera no eran aptos para el tipo de terreno y actividades. Sus explicaciones, en "Carta de Pedro Martínez de Zavala a Su Majestad el Rey, Tucumán, 24 de abril de 1617”, Biblioteca Nacional, Sala Medina, Manuscritos, tomo 118, documento 2085, 180.

${ }^{28} \mathrm{La}$ información proviene del informe del oidor Machado que comentaremos más adelante.
} 
siglo XVII tenía alrededor de mil hombres y el doble de indios aliados o "amigos"29. Cada ocho soldados consumían una vaca por semana y cada soldado llevaba alrededor de seis caballos durante las campañas, de modo que cualquier incremento en el número de soldados significaba automáticamente un incremento significativo de ganado que, como dijimos, no era un recurso abundante en el Valle Central. Por eso, la presencia del ejército en el sur de Chile (con la disponibilidad de un situado que aunque era irregular, existía como base del crédito para la compra de recursos) organizó una extensa red comercial en el sur del imperio español ${ }^{30}$.

Paradójicamente también, mientras más ganado había en el lado español, más tentación había para los ataques de los indios. La corona en este sentido estaba bien informada y los virreyes rechazaban los pedidos de aumentar el número de tropas para terminar la guerra. Hacia mediados del siglo XVII las autoridades tenían una idea bastante clara sobre el límite al incremento de tropas que imponía la disponibilidad de ganado. El ejército de Chile jamás podría sobrepasar los 5.000 hombres, incluyendo a los indios amigos ${ }^{31}$. Tácticas militares en los bosques también aconsejaban utilizar infantes en lugar de caballería Por eso los comandantes preferían infantes para evitar al mismo tiempo los malones de nativos para robar los caballos y las dificultades durante las campañas cuando los indios quemaban los pastos. Las autoridades sabían que más hombres aumentaba tantos los costos como las dificultades, tal como sintéticamente concluía un informe: "mientras más somos, peor nos va"32.

La necesidad de sostener la presencia militar española con infantes llevó a justificar el mantener un alto número de aliados indígenas en el ejército, cuyos servicios se pagaban con ganado y ropas; y a veces también con efectivo. Antes de mediados del siglo XVII, el número de estos amigos prácticamente igualaba o superaba al de los españoles. Y más interesante incluso: estos amigos eran quienes realizaban casi todas las tareas durante las campañas. Su presencia se había vuelto tan decisiva para la guerra que en 1640 el gobernador Baides informó que una peste había debilitado a los nativos rebeldes, pero también había acabado con los amigos, y sin ellos, afirmaba el gobernador, las campañas eran imposibles, porque los amigos eran quienes guiaban a las tropas por los caminos, nadaban primero los ríos buscando los mejores pasos, juntaban la leña, salían a cazar, entraban en las zonas más peligrosas para quemar y talar las sementeras de los rebeldes, llevaban los caballos a pastar y a beber, cuidaban del ganado, se encargaban de

\footnotetext{
${ }^{29}$ Jerónimo de Quiroga, por ejemplo, un soldado de mediados de siglo XVII aseguró que habían 2.000 soldados y alrededor de 4.000 a 6.000 indios aliados o "amigos" cuyos servicios se pagaban con ganado menor y mayor. Jerónimo de Quiroga, Memoria de los sucesos de la guerra de Chile (Santiago de Chile: Andrés Bello, 1979): 36. Sobre los indios amigos, ver Andrea Ruiz Esquide, Los indios amigos en la frontera araucana (Santiago de Chile: Universitaria, 1993).

${ }^{30}$ He reconstruido estas redes generadas a partir de las necesidades de los mercados en Chile en Margarita Gascón, "Comerciantes y redes mercantiles del siglo XVII en la frontera sur del virreinato del Perú", Anuario de Estudios Americanos 57, no. 2 (2000): 413-448.

${ }^{31}$ Quiroga, Memoria, 421.

32 "Advertencias sobre la guerra de Chile del licenciado Hernando Machado, oidor de la Real Audiencia del Reino de Chile, a Su Magestad el Rey, 14 de marzo de 1621", Biblioteca Nacional de Chile, Sala Medina, Manuscritos, volumen 122 , documento $2172,99-100$.
} 
cocinar. En sus propias palabras, los amigos eran el "nervio de la guerra",33. Las palabras de Baides hacen que uno se pregunte si los que estaban en campaña eran los españoles o los nativos. Pareciera que era una guerra intertribal en la que los españoles "auxiliaban" a los indios, y no al revés ¿Quién servía a quién? Durante un relato sobre el parlamento de Quillín en 1641 esta pregunta vuelve a rondar la interpretación de los hechos. En ocasiones como Quillín, la ceremonia de paz pareciera que tiene lugar entre los indígenas, en presencia de los españoles, esto es, pareciera que los españoles han sido invitados a testimoniar con su presencia el cese de las hostilidades entre las parcialidades de nativos, en virtud de que eran aliados militares de una de esas parcialidades. En otras palabras, la paz no era de los indios con los españoles, sino entre parcialidades de indígenas, donde algunas de ellas estaban aliadas con los españoles, quienes las proveían de ayuda para la guerra ${ }^{34}$.

Volviendo a la peste previa a 1640, el que hubiese reducido a la población nativa era una buena noticia en términos de haber reducido la capacidad bélica de los rebeldes, pero era imposible aprovechar tal debilidad porque, como constató Baides, también el factor demográfico había alterado la disponibilidad de amigos. Poco puede extrañarnos, pues, que la esfera demográfica deba ser considerada como motivo del pedido de cese de fuego que se acordó en el parlamento de Quillín en 1641. La historiografía tradicional, sin embargo, desconoce este desbalance demográfico y, en cambio, acentúa las capacidades negociadoras de Baides; incluso habla del agotamiento y del cansancio entre los nativos que habría provocado la guerra, junto con la necesidad del gobernador Baides para vigorizar la economía regional a través de un cese de hostilidades ${ }^{35}$.

El factor demográfico no es el único ignorado en la historiografía tradicional como elemento explicativo de los cambios en la frontera. Lo mismo ocurre con las catástrofes naturales ${ }^{36}$. Una vez más, el parlamento de Quillín sirve de ejemplo. En 1640 el volcán Villarica entró en erupción y los glaciares de la cumbre se derritieron; los cursos de agua y la laguna se contaminaron con azufre ${ }^{37}$. Los cultivos de los nativos y las reservas de agua fresca sufrieron las consecuencias, privando a los indígenas de sus fuentes de alimentos ${ }^{38}$. Además, sus creencias

\footnotetext{
33 "Carta del Marqués de Baides a don Juan de Solórzano. Concepción, 18 de marzo de 1641 (varios asuntos del gobierno)", Biblioteca Nacional de Chile, Sala Medina, Manuscritos, volumen 137, documento 2485, 101.

${ }^{34} \mathrm{He}$ ampliado esta interpretación en Margarita Gascón, "Fluctuaciones en las relaciones fronterizas en el sur del imperio español (siglo XVII)", Atekna, no. 1 (2003), en prensa.

${ }^{35}$ La historiografía sobre la frontera es abundante principalmente para el siglo XVIII y XIX. Destacamos el trabajo de Alvaro Jara sobre los primeros años de la conquista. En la producción de Sergio Villalobos, Jorge Pinto Rodríguez, Leonardo León Solís, Juan Vargas y Guillaume Boccara las explicaciones sobre el siglo XVII son panorámicas y Quillín es interpretado dentro de uno de los dos esquemas referidos en el texto.

${ }^{36}$ Sobre el impacto de las catástrofes naturales en la vida colonial, ver Margarita Gascón y Esteban Fernández, "Terremotos y sismos en la evolución urbana en Hispanoamérica. Ejemplos coloniales y estudio de caso", Boletín $C F+S$, no. $16(2001)$

${ }^{37}$ La erupción acompañó un periodo de actividad sísmica, con expresiones como los terremotos destructivos en Santiago de 1637 y 1647. Hay relatos antiguos como el de Miguel de Amunátegui, El terremoto del 13 de mayo de 1647 (Santiago de Chile: R.Jover, 1882).

38 "Relación verdadera de las paces que capituló con el Arauco rebelado el Marqués de Baides, conde de Pedrosa, gobernador y capitán general de Chile y presidente de la Real Audiencia. Sacada de los informes y cartas de los
} 
religiosas hacían que venerasen a las montañas en particular, por lo que una erupción era vista como una mala señal. Hay un informe enviado a España que atribuye a los nativos la iniciativa de la paz, pero que los historiadores han descuidado. Al pedir la paz, los indígenas solucionaban al mismo tiempo dos aspectos de su problema porque, por una parte, podían despreocuparse de las campañas de los españoles en sus territorios, y por la otra, conseguían alimentos ya que solían ser los regalos ofrecidos por los españoles para mostrarle a los indígenas los beneficios de la paz ${ }^{39}$.

Debido a que nuestra información sobre las fronteras coloniales proviene casi exclusivamente de los informes oficiales, tendemos a creer que los españoles tenían las iniciativas y estaban en control de la situación. Asimismo, tendemos a narrar que los nativos resistían, se defendían y que reaccionaban frente a las conductas españolas. Pocas veces reflexionamos que tal interpretación deriva de nuestras fuentes. Así por ejemplo, los oficiales y sobre todo los gobernadores tenían escaso interés en narrar el fiasco que significaba encontrarse paralizados porque los indios quemaban los pastos. Era una estrategia simple y efectiva, de modo que reconocerlo dañaba el prestigio militar del que querían rodearse los soldados y oficiales en su ascendente carrera de honores. Los gobernadores, por su parte, jamás explicaban que sus campañas se reducían a un puñado de días porque se vieron privados de elementos para continuar avanzando. Explican, en cambio, que la campaña fue corta pero exitosa, que las sementeras de los indios estaban destruidas y que los nativos pronto solicitarían la paz definitiva. Pero la promesa nunca se materializaba. Nunca los indígenas parecían estar padeciendo de tanta hambre como para apurar la paz. Más bien, el hambre parecía establecerse entre los españoles, ya que los informes denunciaban que las deserciones eran abundantes y que los soldados huían con los indios porque éstos tenían mucha comida y muchas mujeres ${ }^{40}$.

La corona no tardó demasiado en comprender que había algo extraño en tantos informes que decían que los indios rebeldes habían sufrido enormes daños en sus sementeras y poblados, por una parte, y por la otra parte, la realidad de que la frontera seguía activa consumiéndole recursos de la caja de Lima a través del situado. En 1621 el oidor Hernando de Machado envió un

padres de la compañía de Jesús que acompañaron el Real ejército en la jornada que hizo para este efecto el año pasado de 1641 (Madrid 1642)", de Alonso de Ovalle (1601-1651) en la Colección de Libros Raros o Curiosos. Tomo XIII. También en la John Carter Brown Library. Dice la relación que "[...]" en la tierra del cacique Aliante reventó un volcán” (245), “[...] piedras y cenizas en el río Alipen cocieron los peces [...] hirvieron las corrientes del río Toltén [...] cuatro meses no se pudieron beber sus aguas ni probar pescado [...] mal olor y sabor a azufre [...] aguas espesas por las cenizas" (246), “[...]la laguna de Villarica creció e inundó los pueblos de los indios” (247).

39 "Junta de Guerra. Consejo de Indias. Madrid. Para conocer el estado de la guerra de Arauco sigue una carta del Marqués de Baides. 1643”. Biblioteca Nacional de Chile, Sala Medina, Manuscritos, volumen 137, documento 2514, 398.

40 "Cartas de varios (1621)", “[...] los indios han hecho 185 entradas desde 1613 a la fecha [...] se han llevado casi 1.000 caballos; [...] se han ido 40 y tantos soldados con los indios", Biblioteca Nacional de Chile, Sala Medina, Manuscritos, volumen 122, documento 2190, 329. "Nómina de los que han muerto de hambre desde el 20 de agosto del año pasado que faltó la ración hasta el 23 de enero de este año que fue recibido el cargo de corregidor y capitán", Biblioteca Nacional de Chile, Sala Medina, Manuscritos, volumen 106, documento 1707, 223. Según este informe hubo 61 desertores, entre los cuales se encontraba el cirujano, y diez mujeres; se apresaron y se ajusticiaron a un alférez, un soldado y una mujer mestiza. 
informe que echaba bastante luz sobre la dinámica que ya se había establecido en esta frontera. Indicaba que los araucanos controlaban el acceso a los recursos y, a través de esto, controlaban el desarrollo de la guerra. El informe explícitamente señalaba que, al quemar los pastos, los nativos sabían con antelación las rutas que tomarían las tropas españolas y que, en gran medida, esto ocurría porque los españoles siempre usaban las mismas rutas, que eran las rutas que ya conocían por las campañas anteriores. Por eso año tras año avanzaban aproximadamente hasta la misma latitud donde se encontraban sin pastos ya que los indios habían procedido a quemarlos. "Sin apartarse ni una legua" dice nuestro informante, las tropas volvían a los fuertes. Las acciones no terminaban ahí, porque los araucanos plantaban pequeñas porciones de tierra con granos cerca de las rutas por donde ya sabían que pasarían los españoles. Los españoles las destruían antes de volver a los fuertes donde, muy satisfechos, escribían a Su Majestad que habían "causado grandes daños a las sementeras de los indios". Pero las sementeras que alimentaban a los indios estaban en los valles intermontanos de difícil acceso para los españoles. Los movimientos de las tropas y de los rebeldes, como en un minué graciosamente coordinado, hacían que Machado concluyese en que "los indios de Chile sólo se mueren de risa" ${ }^{41}$

Las estrategias de los nativos para controlar los avances de los españoles eran poco dramáticas en cuanto a que nos faltan las grandes batallas, decisivas, pero eran estrategias terriblemente efectivas en términos de costo-beneficio, ya que prácticamente los indígenas no debían arriesgar ni hombres ni recursos. Todo lo contrario ocurría en el lado español, donde la corona debía enviar hombres y dinero para su control, a pesar de que el control era por razones estratégicas ligadas a su política continental en Europa. De cualquier modo, saber que los rebeldes "se morían de risa" les debía causar muy poca gracia.

\footnotetext{
41 “Advertencias sobre la guerra”, 100.
} 


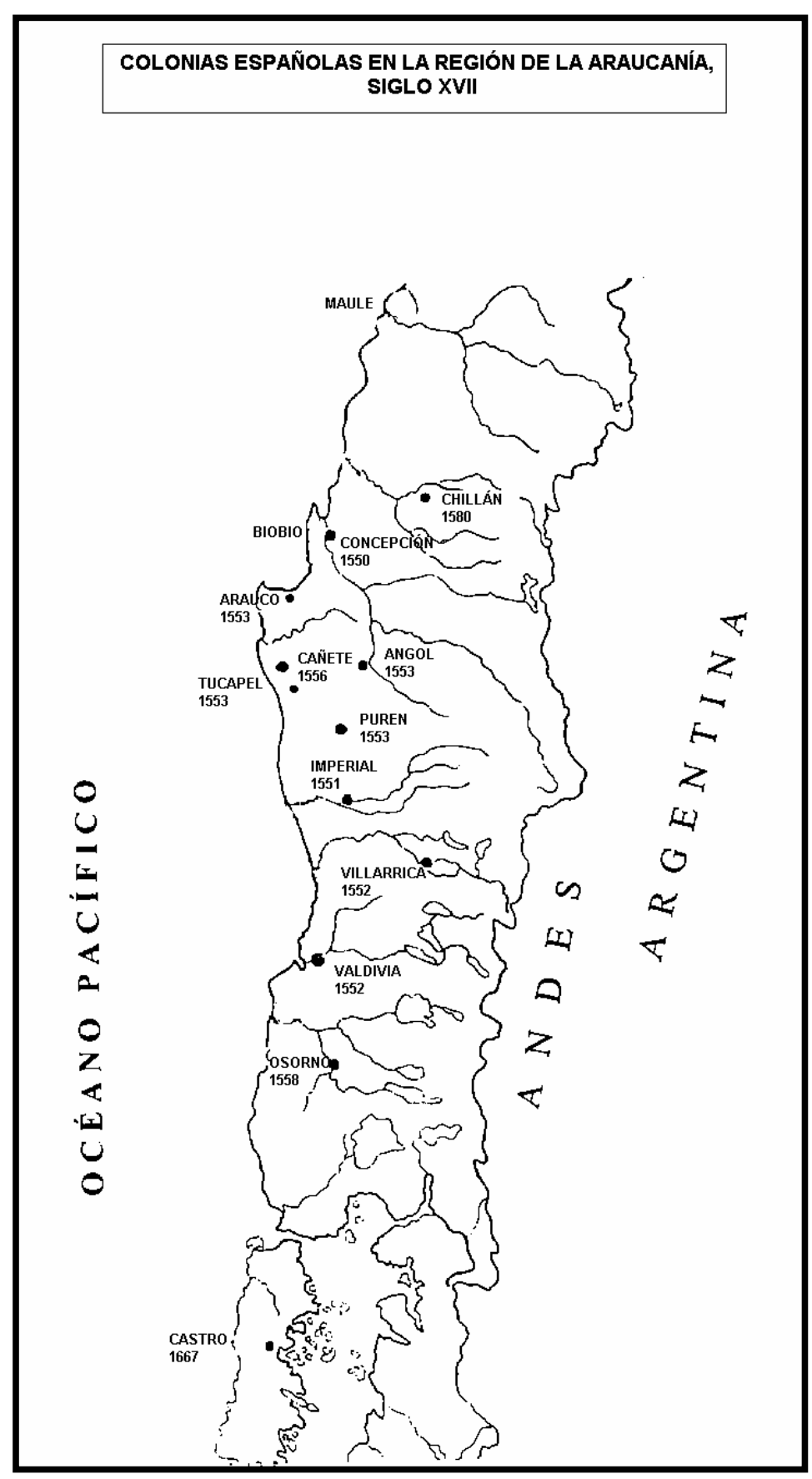

Mapa 3. Colonias españolas en la región de la Araucanía, siglo XVII. 
El otro elemento que alimentó la persistencia de la frontera fue el situado, a pesar de que fue impuesto para tener un mejor ejército que permitiese pacificar la zona en un corto periodo. Pero el remedio se había convertido en veneno, según la acertada frase del padre Diego de Rosales en $1672^{42}$. Hacia mediados del siglo XVII el situado ya había llegado a los 3.500 .000 ducados (aproximadamente 2.520 .000 pesos); aunque en otro informe el monto llegaba a más de cuatro millones, y esto exclusivamente para el período entre 1607 y $1620^{43}$. Para tener cierta perspectiva sobre lo que significaba esa cifra, el situado para Florida era de aproximadamente 50.000 pesos por año ${ }^{44}$. Saber que había cuatro millones invertidos en sostener un patrón de comportamientos como los que describía Machado explica la obstinada negativa de aumentarlo, bajo ningún concepto. Pero la imposibilidad de revertir completamente la situación estaba, como señalamos, en el campo de las fuerzas imperiales ya que Chile era vital en la defensa de Potosí. Si se armaba una expedición contra Perú y el Alto Perú en América, ésta debía salir desde Chile. Hacer una expedición desde otro centro, como Buenos Aires, implicaba dificultades profundas y la prueba es que dos siglos más tarde, durante las guerras de la independencia, Buenos Aires envió tres expediciones al Alto Perú por tierra que fracasaron una tras otra. Cuando el general José de San Martín se hizo cargo de las campañas militares, como hombre entrenado en academias militares españolas, aplicó la estrategia de los Austrias, es decir, partió de Buenos Aires, preparó el ejército en Mendoza, aseguró Chile primero y luego desde allí por mar, emprendió la campaña para tomar Lima.

Hay otro aspecto interesante de la relación entre las esferas de recursos, población y conocimiento. Debido a que tanto los soldados españoles como los indios amigos recibían parte de su pago en bienes como comida y ropas, el acceso a los recursos naturales en el Valle Central ocasionaba frecuentes altercados entre los gobernadores y los civiles. Los gobernadores necesitaban acceder a la mayor cantidad de recursos a pagar con el situado al menor precio posible para mantener a las tropas en condiciones aceptables. En la capital, por su parte, la elite encontraba enormes ventajas en tomar lo que pudiese quedar disponible de los beneficios del situado, después de que los comerciantes limeños hubiesen hecho su parte del negocio y procurar que los precios en el mercado ganadero fuesen altos para maximizar la ganancia. Aunque el situado era irregular en su llegada a Chile y debía ir directamente a la frontera, es decir a Concepción, los pedidos de importación de ganado, los cupos para el ejército y su precio se discutían en el cabildo de Santiago. En efecto, las actas del cabildo de Santiago testimonian las reuniones donde los gobernadores presionaban y los comerciantes se defendían, con algunos momentos de tensiones bastantes agudas e indisimuladas durante los gobiernos de Rivera a

\footnotetext{
42 "Informe del Padre Diego Rosales elevado a Su Magestad el Rey para ver y conferir si los indios de Chile después del alzamiento de 1655 serán esclavos. Concepción, 20 de marzo de 1672", Biblioteca Nacional de Chile, Sala Medina, Manuscritos, tomo 162, documento 3250, 26.

43 "Carta de Ginés de Lillo al Virrey del Perú. Yumbel, 19 de febrero de 1621", Biblioteca Nacional de Chile, Sala Medina, Manuscritos, volumen 122, documento 2166. Después del establecimiento del ejército real en Chile, el situado se incrementó de 70.000 ducados a 140.000 en una primera instancia, luego trepó a 212.000 , monto que permaneció sin variaciones para el resto del siglo XVII.

${ }^{44}$ Amy Turner Bushnell, Situado and Sabana. Spain's Support System for the Presidio and Mission Provinces of Florida (Athens: American Museum of Natural History, 1994), 44, 47.
} 
principios de siglo y de Francisco Lazo de la Vega (1629-39) ${ }^{45}$. Poco sorprende que los gobernadores preferidos de la elite en Santiago fueron aquellos que, como Baides, pasaban más tiempo en Concepción que en Santiago, donde la elite capitalina daba rienda suelta a sus ambiciones, despreocupándose de la vigilancia o de los pedidos de auxilio para la frontera que efectuaban los gobernadores.

En defensa de la elite hay que decir que no era poco lo que estaba en juego. El ejército consumía alrededor de 7.000 cabezas de ganado vacuno por año. Por su parte, Santiago exportaba anualmente unos 30.000 quintales de sebo al Perú ${ }^{46}$. Como una vaca rinde un quintal, se necesitaban más de 40.000 vacas anualmente para mantener la economía de la frontera y la economía civil funcionando al mismo tiempo. Pero como ya dijimos, la tierra productiva en el Valle Central era limitada, de modo que para reducir las tensiones que provocaba el aumento demográfico por la existencia de las tropas en el sur y la falta de suficientes recursos naturales, comenzó a importarse ganado desde las provincias del Tucumán y del Río de la Plata. Aun la lejana provincia del Paraguay se integró al circuito generado por la necesidad de recursos del reino de Chile. Muy temprano en el siglo XVII comenzaron a realizar su ruta hacia Santiago y la frontera las caravanas con indígenas paraguayos, yerba mate y tabaco. Quienes más se beneficiaron de esta ruta fueron los jesuitas, ya que realizaban estos envíos como si fuesen de un colegio a otro para evitar así el pago de algunos impuestos ${ }^{47}$.

Los beneficios económicos que la presencia de las tropas con su situado volcaban en la economía regional mantuvieron la frontera activa durante décadas. Con escasa población y bienes a nivel local, la existencia de la frontera aseguraba condiciones de ingreso de recursos desde otras regiones del virreinato. Esto hizo fracasar intentos de pacificación como fue la guerra defensiva propuesta por el jesuita Luis de Valdivia. Su propuesta era factible, si solamente los beneficios de la guerra no hubiesen sido más importantes, como el mismo Valdivia afirmó al ver que se desmoronaba su acción, porque acabar con la guerra significaba acabar con "el principal ingreso económico para una región que se encontraba despoblada y arruinada por la guerra" ${ }^{, 8}$. Contradictoriamente, sin embargo, el propio sueldo de Valdivia y de sus misioneros jesuitas se pagó con ese situado, a pesar de ser el culpable de los males ${ }^{49}$.

\footnotetext{
${ }^{45}$ También aparece en la bibliografía como Laso de la Vega. La ortografía original del siglo XVII es con doble ese, ver John Carter Brown Library: Santiago de Tesillo (n.1607), Guerra de Chile. Causas de su duración, medios para su fin: exemplificado en el gobierno de don Francisco Lasso de la Vega (Madrid: Imprenta Real, 1647).

${ }^{46}$ Agustín Carrillo de Ojeda (1603-1671), Señor. Obligación es, que nació con el vasallo, dar noticia a su rey, y a sus ministros, que goviernan su monarquía, de lo que pide remedio (Madrid: 1659), 17.

${ }^{47}$ Gascón, "Comerciantes y redes", 413-448.

${ }^{48}$ John Carter Brown Library: Luis de Valdivia, “Señor, El Padre Luis de Valdivia de la Compañía de Iesus, Digo que siendo VM informado de la importancia grande de cortar la guerra de Chile [...]" (Madrid [?]: 1610 [?]; Boston, 1928). Existe una importante bibliografía sobre Luis de Valdivia y su obra; una reciente contribución es Rolf Foerster, Jesuitas y Mapuches, 1593-1767 (Santiago de Chile: Universitaria, 1996).

${ }^{49}$ El virrey Marqués de Guadalcazar informó en 1623 que "son muy crecidas las ayudas de costo que se dan a los padres de la Compañía en Chile" y que se habían ofrecido dominicos para hacer estas misiones por mucho menos dinero. "Carta del Virrey del Perú, Marqués de Guadalcazar, a Su Magestad el Rey, Reyes, 24 de mayo de 1623 (hacienda)". Biblioteca Nacional de Chile, Sala Medina, Manuscritos, tomo 126, documento 2286, 269-270.
} 
El meteórico ingreso de gente (tropas) y de capital (situado) transformó a una región que la rebelión indígena ya había alterado a principios del siglo XVII. En efecto, la batalla de Curalaba en 1599 había cerrado el ciclo de la colonización española en el sur de Chile, a lo que le siguió la pérdida de mano de obra en forma de nativos encomendados y la pérdida de territorio fértil; ambos elementos difícilmente podían ser compensados por la economía y por la población que se ubicaba en el Valle Central. Los gobernadores temían la capacidad bélica de los indígenas rebeldes, pero más temían al hambre entre sus hombres. Mientras, los civiles reconocían la importancia de mantener tropas en el sur, pero les costaba aceptar que debían contribuir a su mantenimiento y sistemáticamente se quejaban de la pobreza del reino. Como forma de disminuir esas tensiones, las consecuencias de la presencia de la frontera militar se expandieron a las colonias ubicadas en la vertiente oriental de los Andes. Pronto comenzaron a ser los lugares de donde se extraían los recursos para Chile, vía comercio, pero también vía caza de ganado cimarrón en Cuyo y en el sur de Córdoba y de Buenos Aires. Y no sólo se expandieron en esta dirección los españoles; también los araucanos lo hicieron, aunque a un ritmo diferente al que tuvo la expansión española ${ }^{50}$. De este modo, la frontera sur del imperio, que se militarizó a principios del XVII con la esperanza de una rápida pacificación, no solamente permaneció durante el resto del periodo colonial, sino que incluso expandió sus efectos hacia las provincias trasandinas.

\section{Conclusión}

Hemos propuesto un modelo de interacción de tres esferas (población, recursos y conocimiento) en el campo de fuerzas imperiales, como otra forma de entender el surgimiento y la evolución de nuestras fronteras en las Américas. Estas tres esferas se relacionaron entre sí dentro de un campo de fuerzas determinado por las decisiones imperiales, principalmente por las decisiones estratégicas de defender las espaldas de Lima y Potosí. Con este modelo superamos los inconvenientes de los enfoques más tradicionales de la historiografía, donde los conceptos relacionados con la frontera se encuentran cargados por décadas de discusiones, como ocurre principalmente con el concepto de frontera en Estados Unidos por la influencia de Turner.

Nuestro análisis partió de que la disponibilidad de recursos naturales en una determinada área ayuda a dar explicaciones sobre la evolución de las sociedades coloniales, y especialmente de aquellas sociedades de frontera porque, de diversas maneras, los recursos disponibles estructuraron las relaciones entre las sociedades europeas y nativas. En el proceso, la esfera de la población y del conocimiento interfieren también permanentemente en las relaciones que una sociedad establece con su ambiente. Analizamos con este modelo a la frontera en Arauco en el momento de su militarización, es decir, a principios del siglo XVII porque esta decisión de la corona modificó drásticamente la situación de la región, tanto en términos de recursos como de población y comprobamos que el modelo nos obliga a prestar atención a varios aspectos,

\footnotetext{
${ }^{50}$ He analizado este proceso de expansión y sus consecuencias durante la segunda mitad del siglo XVII y primera mitad del XVIII en Margarita Gascón, "La articulación de Buenos Aires a la frontera sur del Imperio Español, 16401740”, Anuario IEHS, no. 13 (1998): 193-214.
} 
algunos como el rol de las catástrofes naturales que han sido usualmente negados o poco estudiados por la historiografía tradicional.

\section{Bibliografía}

Aguirre, Miguel de. Población de Baldivia. Lima: Julián Santos, 1647.

Amunátegui, Miguel de. El terremoto del 13 de mayo de 1647. Santiago de Chile: R.Jover, 1882.

Barth, Frederick. Ethnic Groups and boundaries: the social organization of culture difference. Boston: Little Brown, 1990.

The Anthropology of Ethnicity. The Hague: Spinhuis, 1994.

Blancpain, Pierre. Araucans et la Frontière dans l'histoire du Chili des origines au XIXe siècle: Une épopée américaine. Vervuert: Frankfurt am Main, 1990.

Boccara, Guillaume. "Etnogénesis mapuche. Resistencia y reestructuración entre los indígenas del centro-sur de Chile (siglo XVI-XVIII)". Hispanic American Historical Review 79, no. 3 (1999): 425-461.

Borah, Woodrow W. La demografia histórica de la América Latina: fuentes, técnicas, controversias, resultados. Bogotá: Universidad Nacional de Colombia, 1972.

Borah, Woodrow W. y Sherburne F. Cook. The Aboriginal Population of Central Mexico on the Eve of the Spanish Conquest. Berkeley: University of California Press, 1963.

Botana, Natalio. El orden conservador. La política argentina entre 1880 y 1916. Buenos Aires: Sudamericana, 1977.

Borde, Jean y Mario Góngora. Evolución de la propiedad rural en el Valle del Puangue. 2 Vols. Santiago de Chile: Universitaria, 1956.

Burns, Robert. "The Significance of the Frontier in the Middle Ages". En Robert Bartlett y Angus Mackay, eds. Medieval Frontier Societies. Oxford: Clarendon Press, 1996: 30739.

Calvo, Thomas, Woodrow Borah, et al. Historia y población en México: siglos XVI-XIX. México, D.F.: Colegio de México, 1994.

Campos, Fernando. Historia de Concepción, 1550-1970. Santiago de Chile: Universidad Técnica del Estado, 1979.

Carmagnani, Marcello. Los mecanismos de la vida económica en una sociedad colonial. Santiago de Chile: DIBAM, 2001.

Caro de Torres, Francisco. Relación de los servicios que hizo a su magestad del Rey don Felipe Segundo y Tercero, don Alonso de Sotomayor. Madrid: 1620.

Carrillo de Ojeda, Agustín. Señor. Obligación es, que nació con el vasallo, dar noticia a su rey, y a sus ministros, que goviernan su monarquía, de lo que pide remedio. Madrid: s/d, 1659.

Cartwright, Frederick. Disease and History. Nueva York: Barnes and Noble, 1991.

Cook, Noble D. Demographic collapse, Indian Peru, 1520-1620. Cambridge y Nueva York: Cambridge University Press, 1981. 
Born to die: disease and New World conquest, 1492-1650. Cambridge y Nueva York: Cambridge University Press, 1998.

Cook, Noble D. y W. George Lovell, eds. Secret judgments of God: Old World disease in colonial Spanish America. Norman: University of Oklahoma Press, 1991.

Crosby, Alfred. Ecological Imperialism. Cambridge: University of Cambridge Press, 1999.

Cunningham, Andrew y Ole P. Grell. The Four Horsemen of the Apocalypse. Religion, War, Famine and Death in Reformation Europe. Cambridge: Cambridge University Press, 2000.

Daniels, Christine y Michael Kennedy, eds. Negotiated Empires. Centers and Peripheries in the Americas, 1500-1820. Nueva York: Routledge, 2002.

Faragher, John. Re-reading Frederick Jackson Turner. The significance of the Frontier in American History and other Essays. Nueva York: Holt, 1994.

Ferrando, Ricardo. Y así nació la frontera. Santiago de Chile: Antártica, 1986.

Fleusche, Della y Eugene Korth. Forgotten Females. Women of African and Indian Descent in Colonial Chile, 1535-1800. Detroit: Ethridge, 1983.

Foerster, Rolf. Jesuitas y Mapuches, 1593-1767. Santiago de Chile: Editorial Universitaria, 1996.

Gascón, Margarita. "The Military of Santo Domingo, 1720-1764". Hispanic American Historical Review 73, no. 3 (1993): 431-452.

"La articulación de Buenos Aires a la frontera sur del Imperio Español, 1640-1740". Anuario IEHS, no. 13 (1998): 193-214.

"Comerciantes y redes mercantiles del siglo XVII en la frontera sur del virreinato del Perú". Anuario de Estudios Americanos 57, no. 2 (2000): 413-448.

"La transición de periferia a frontera: Mendoza en el siglo XVII". Revista Andes, no. 12 (2001): 175-199.

"Frontier Societies: A View from the Southern Frontier of the Indies". Working Paper. Cambridge: Harvard University, 2002.

"Fluctuaciones en las relaciones fronterizas en el sur del imperio español (siglo XVII)". Atekna, no. 1 (2003). En prensa.

Gascón, Margarita y Esteban Fernández. "Terremotos y sismos en la evolución urbana en Hispanoamérica. Ejemplos coloniales y estudio de caso". Boletín $C F+S$, no. 16 (2001).

Góngora, Mario. Encomenderos y estancieros. Estudios acerca de la constitución social aristocrática de Chile después de la conquista. Santiago de Chile: Universidad de Chile, 1970.

Grimson, Alejandro, comp. Fronteras nacionales e identidades. Buenos Aires: Ciccus, 2000.

Guerra de Chile. Causas de su duración, medios para su fin: exemplificado en el gobierno de don Francisco Lasso de la Vega. Madrid: Imprenta Real, 1647.

Guy, Donna y Thomas Sheridan, eds. Contested Grounds. Comparative Frontier on the Northern and Southern Edges of the Spanish Empire. Tucson: The University of Arizona Press, 1998.

Halperín Donghi, Tulio. Proyecto y construcción de una nación (Argentina 1846-1916). Caracas: Biblioteca Ayacucho, 1980. 
Herlihay, David. The Black Death and the Transformation of the West. Cambridge: Harvard University Press, 1997.

Inostrosa, Iván. Historia de Concepción. Temuco: Universidad de la Frontera, 1998.

Jacobs, Wilbur. On Turner's Trail. Lawrence: University Press of Kansas, 1994.

Klein, Herbert. The American Finances of the Spanish Empire: Royal Income and Expenditures in Colonial Mexico, Peru and Bolivia, 1680-1809. Albuquerque: University of New México Press, 1998.

Klein, Kervin L. Frontiers of Historical Imagination. Narrating the European Conquest of North America, 1890-1990. Berkeley: University of California Press, 1999.

León, Leonardo. Maloqueros y conchavadores en la Araucanía y las Pampas, 1700-1800. Temuco: Universidad de la Frontera, 1991.

Mariño de Lovera, Pedro. "Crónica del Reino de Chile". En Biblioteca de Autores Españoles Madrid: Atlas, 1960.

Méndez, Luz. "Trabajo indígena en la frontera araucana de Chile". Jarhbuch, no. 24 (1987): 213-250.

Mörner, Magnus. Evolución demográfica de Hispanoamérica durante el periodo colonial. Stockholm: Institute of Latin American Studies, 1979.

Muñoz, Juan Guillermo, ed. Instituciones y funcionarios en Chile colonial. Serie Nuevo Mundo 7. Santiago de Chile: Universidad de Chile, 1992.

Ratto, Héctor. Actividades marítimas en Patagonia durante los siglos XVII y XVIII. Buenos Aires: Kraft, 1930.

Nobles, Gregory. American Frontiers. Nueva York: Hill \& Wang, 1997.

Operé, Fernando. Historia de las fronteras: el cautiverio en la América hispánica. Buenos Aires: FCE, 2001.

Oszlack, Oscar. La formación del estado argentino. Buenos Aires, Belgrano, 1985.

Pinto, Jorge, ed. Araucanía y Pampas. Un mundo fronterizo en América del Sur. Temuco: Universidad de la Frontera, 1996.

Power, Daniel y Naomi Standen, eds. Frontiers in Question. Eurasian Borderlands, 700-1700. Londres: McMillian, 1999.

Prescott, J.R.V. Boundaries and Frontiers. Londres: Croom Helm, 1978.

Robinson, David J. ed. Studies in Spanish American population history. Boulder: Westview Press, 1981.

Quiroga, Jerónimo de. Memoria de los sucesos de la guerra de Chile. Santiago de Chile: Andrés Bello, 1979.

Retamal, Julio. Testamentos de Indios en Chile Colonial, 1564-1801. Santiago de Chile: Universidad Andrés Bello, 2000.

Ruiz Esquide, Andrea. Los indios amigos en la frontera araucana. Santiago de Chile: Universitaria, 1993.

Sábato, Hilda y Alberto Lettieri, comps. La vida política en la Argentina del siglo XIX. Armas, votos y voces. Buenos Aires: Fondo de Cultura Económica, 2003.

Sahlins, Peter. Boundaries: The Making of the France and Spain in the Pyrenees. Berkeley: University of California Press, 1989. 
Te Paske, John. "The Costs of Empire: Spending Patterns and Priorities in Colonial Peru, 15811820". Colonial Latin American Historical Review 1, no. 2 (1993): 1-34.

Turner, Amy. Situado and Sabana. Spain's Support System for the Presidio and Mission Provinces of Florida. Athens: American Museum of Natural History, 1994.

Turner, Frederick J. Frontier and Section. Selected Essays of Frederick Jackson Turner. Englewood Cliffs: Prentice Hall, 1961.

Vargas, Juan. "Estilo de vida en el ejército de Chile durante el siglo XVII". Revista de Indias 53, no. 198 (1993): 425-438.

Villalobos, Sergio. Los Pehuenches en la vida fronteriza. Santiago de Chile: Universidad Católica de Chile, 1989.

Wallerstein, Immanuel. The Modern World System. Vol. 1. New York: Academic Press, 1974.

Watts, Sheldon. Epidemics and History: Disease, Power and Imperialism. New Haven: Yale University Press, 1997.

Weber, David y Jane Rausch, comps. Where Cultures Meet. Frontiers in Latin American History. Wilmington: S.R.Books, 1994.

Zapater, Horacio. Los aborígenes chilenos a través de cronistas y viajeros. Santiago de Chile: Universitaria, 1973.

Fecha de recepción del artículo: 21 de abril de 2003.

Fecha de aceptación: 22 de agosto de 2003. 